\title{
Challenges in modeling detailed and complex environmental data sets: a case study modeling the excess partial pressure of fluvial $\mathrm{CO}_{2}$
}

\author{
Amira Elayouty ${ }^{1}$ - Marian $\operatorname{Scott}^{1}$. \\ Claire Miller ${ }^{1}$. Susan Waldron ${ }^{2}$. \\ Maria Franco-Villoria ${ }^{3}$
}

Received: 8 December 2014 / Revised: 15 June 2015 / Published online: 11 September 2015

C The Author(s) 2015. This article is published with open access at Springerlink.com

\begin{abstract}
Advances in sensor technology enable environmental monitoring programmes to record and store measurements at a high temporal resolution, enhancing the capacity to detect and understand short duration changes that would not have been apparent in the past with monthly, fortnightly or even daily sampling. However, there are various challenges in terms of the processing and analysis of these environmental high-frequency data due to their complex behavior over the different timescales and the strong correlation structure that persists over a large number of lags. Here, we explore the complexities of modeling high-frequency data which arise from environmental applications. With increasing understanding of the importance of surface waters as a source of atmospheric $\mathrm{CO}_{2}$ we consider a high-resolution sensor-generated time series of the over-saturation of $\mathrm{CO}_{2}, \mathrm{EpCO}_{2}$, in a small order river system. We will present advanced statistical approaches to analyze and model the data, which include visualization tools for exploratory analysis, wavelets and additive models. These methods reveal the complex dynamics of $\mathrm{EpCO}_{2}$ over different timescales, and the multivariate relationships of $\mathrm{EpCO}_{2}$ with hydrology and temporal autocorrelation structures, which are time and scale dependent.
\end{abstract}

Handling Editor: Bryan F. J. Manly.

Electronic supplementary material The online version of this article (doi:10.1007/s10651-015-0329-4) contains supplementary material, which is available to authorized users.

Amira Elayouty

a.el-ayouti.1@ research.gla.ac.uk

1 School of Mathematics and Statistics, University of Glasgow, Glasgow, Scotland, UK

2 School of Geographical and Earth Sciences, University of Glasgow, Glasgow, Scotland, UK

3 Department of Economics and Statistics, University of Torino, Turin, Italy 
Keywords Excess partial pressure of carbon dioxide - Generalized additive models . Hydrological high-frequency data . Wavelets

\section{Introduction}

Understanding the drivers of crucial environmental challenges, such as climate change, water and air pollution, changes in water quantity, and loss of soil carbon is of great importance to society (Intergovernmental Panel on Climate Change IPCC 2013). Therefore, environmental monitoring technologies are continually being developed to enhance the ability to understand environmental systems and detect changes occurring within these systems. In the past, environmental monitoring programmes typically involved monthly, fortnightly, weekly, and occasionally daily sampling campaigns but rarely shorter time intervals (Kirchner et al. 2004; Neal et al. 2012). However, in reality, most environmental processes are continuous in time with changes potentially occurring at sub-daily scales; and hence monitoring programmes of high temporal resolution are needed to observe and understand the significance of these rapid changes. Sensor technology is continuously developing and as a result, the ability to record and store measurements is ever-improving (Yick et al. 2008). Accordingly, environmental monitoring programmes make use of these sensors to record hourly or sub-hourly (e.g., every minute) measurements (Moraetis et al. 2010). Sensor hydrological data recorded at short time frames over a long time period are referred to as "Hydrological HighFrequency Data (HHFD)" (Kirchner et al. 2004). Such HHFD allow us to address new research questions which were previously inaccessible, although they pose statistical modeling and analysis challenges. Many of the currently available standard statistical methods and software tools are not designed to properly manipulate the complexity of such volumes of data (Kirchner et al. 2004) and hence advanced statistical methods are needed to analyze and model these large complex datasets.

Here, we investigate the complexities in the modeling and analysis of hydrological high-frequency data, such as persistent correlation between observations, complex dynamics and interactions over the different timescales. High-resolution sensorgenerated time series of partial pressure of carbon dioxide in a small catchment is used as an illustrative dataset. The aqueous partial pressure of carbon dioxide is a measure of the capacity for $\mathrm{CO}_{2}$ exchange between the water and the atmosphere ( $\mathrm{Li}$ et al. 2012). The excess partial pressure of carbon dioxide $\left(\mathrm{EpCO}_{2}\right)$ in surface freshwater is a dynamic representation of the interacting biogeochemical and hydrological processes that produce, consume, and transport carbon dioxide (Waldron et al. 2007). If the river is over-saturated (an excess partial pressure, $>1$ ), $\mathrm{CO}_{2}$ can be effluxed, representing direct linkage of terrestrial and atmospheric carbon cycles (Butman and Raymond 2011). As surface waters are capable of degassing large amounts of $\mathrm{CO}_{2}$ to the atmosphere (Raymond et al. 1997; Cole et al. 1994; Richey et al. 2002; Li et al. 2013; Yao et al. 2007), they have been included recently in the assessment of the global carbon budget (Butman and Raymond 2011). Therefore, understanding of the temporal variability in the capacity for degassing and the drivers of such variability is of value in refining uncertainity over such estimates. 
Many studies have examined the temporal and spatial variations of $\mathrm{EpCO}_{2}$ and the mechanisms controlling these variations in some high and low order rivers and large lotic systems (Butman and Raymond 2011; Cole et al. 1994; Dawson et al. 2009; Raymond et al. 1997; Richey et al. 2002; Li et al. 2012, 2013; Yao et al. 2007). All these studies show that high-order rivers are important sources of atmospheric $\mathrm{CO}_{2}$ and low-order rivers also contain high concentrations of dissolved $\mathrm{CO}_{2}$ (Butman and Raymond 2011). High-order rivers are over-saturated. For example, the Hudson River, which flows from north to south through eastern New York in the United States, is over-saturated with $\mathrm{CO}_{2}$ and $\mathrm{EpCO}_{2}$ exhibits a diel cycle reaching its maximum in summer (Raymond et al. 1997). The evasion of $\mathrm{CO}_{2}$ from rivers of the central Amazon basin constitutes an important carbon loss process and there is a pronounced seasonality in evasion linked to wet and dry seasons (Richey et al. 2002). However, the estimates of the effluxed $\mathrm{CO}_{2}$ are uncertain because of the large temporal and spatial variability. $\mathrm{EpCO}_{2}$ dynamics at six sites in the lower reaches of Xijiang River, southern China, were difficult to interpret due to sampling frequency-monthlybeing insufficient (Yao et al. 2007). Daily measurements have proved more useful in understanding the spatio-temporal dynamics e.g., in the upper Yangtze River basin in China ( $\mathrm{Li}$ et al. 2012). Therefore, high-frequency sampling in space and time is required due to the spatio-temporal heterogeneity in the catchment characteristics and anthropogenic activities.

Sub-daily measurements across different seasonal periods should provide sufficient detail to understand fluctuations of free $\mathrm{CO}_{2}$ concentrations at smaller timescales (Dawson et al. 2009). Here, 3 years of $15 \mathrm{~min}$ frequency sensor-generated data are used to investigate and reveal the temporal variations of $\mathrm{EpCO}_{2}$ and explain the mechanisms controlling these variations in a small-order river. This long-term hydrological high-frequency dataset encompasses seasonality and varying time periods between hydrological events, but also allows many new features, including pulses and short duration events to be identified, which would not have been apparent with monthly or daily sampling.

To date, the temporal variations of $\mathrm{EpCO}_{2}$ and the mechanisms controlling these variations have been considered using simple graphs, descriptive statistics, linear regression and multivariate statistics such as correlation analysis and analysis of variance (Raymond et al. 1997; Li et al. 2013, 2012; Yao et al. 2007; Dawson et al. 2009). But, the dynamic responses of hydrological high-frequency data are complex and capturing them by conventional visualization and analysis techniques is difficult (Neal et al. 2013). Nowadays, more advanced statistical tools are available and there exist various techniques to study the temporal variations of $\mathrm{EpCO}_{2}$ and its relationship with the hydrodynamics.

To quantify the temporal variations of $\mathrm{EpCO}_{2}$, one can employ frequency analysis, time series decomposition and statistical analysis of the daily, seasonal and annual patterns. However, wavelet analysis provides an alternative method, in which temporal variations are analyzed over a wide range of time frames which are not pre-assigned. Another key advantage of wavelets is that they are useful in analyzing non-stationary time series by capturing the local variations in both time and frequency domains. Examples of using wavelets in analyzing hydrologic time series can be found in FrancoVilloria et al. (2012), Labat (2005), Sen (2009) and White et al. (2005). In view of 
that, wavelets present a convenient exploratory tool to study the different temporal variations of the non-stationary time series of $\mathrm{EpCO}_{2}$. Another objective for the paper is to model the temporal variations in $\mathrm{EpCO}_{2}$ and its relationships with hydrodynamics. Additive models offer a very useful framework which allows complex and non-linear relationships, which are not known a priori, to be modeled in a flexible regression structure using non-parametric smooth functions (Hastie and Tibshirani 1990). Hence, additive models can provide a powerful tool to investigate the temporal trends of the $\mathrm{EpCO}_{2}$ along with its cyclical and seasonal variations and its relationship with the river hydrology over the study period. Examples of additive models applied to hydrologic time series can be found in Ferguson et al. (2008) and Miller et al. (2014).

To our knowledge, no research has yet employed wavelets or additive models to analyze the $\mathrm{EpCO}_{2}$ temporal dynamics and its complex relationship with the river hydrodynamics using the high temporal resolution data evaluated here. In this paper, wavelet analysis is first employed to study and determine the temporal variations of $\mathrm{EpCO}_{2}$ over the different timescales to identify the timescales responsible for the major variability. Next, the temporal variations of $\mathrm{EpCO}_{2}$ and its relationship with water hydrology are analyzed and modeled. This latter objective is achieved by fitting a set of hierarchical additive models to describe the variations in $\mathrm{EpCO}_{2}$ over a day, then over a month, and finally over a full hydrological year. Using this temporal hierarchy, models which better explain the processes determining $\mathrm{EpCO}_{2}$ are fitted, incorporating complex multivariate interactions and lagged variables to account for the persisting temporal correlations at the different timescales.

\section{Materials and methods}

\subsection{Study site}

The study site is in the Glen Dye catchment close to the terrestrial-aquatic interface of the River Dee in Aberdeenshire. Glen Dye is located in North-East Scotland at $56^{\circ} 56^{\prime} 27 \mathrm{~N}$ and $2^{\circ} 36^{\prime} 00 \mathrm{~W}$. It is a headwater sub-catchment of the River Dee, a highorder river draining into the North Sea. The sensors were deployed at the Scottish Environment Protection Agency (SEPA) Charr gauging flume on the Water of Dye, a $41.7 \mathrm{~km}^{2}$ catchment. Glen Dye is mainly upland in character, with altitude ranging between 100 and $776 \mathrm{~m}$. The climate is cold, with mean annual precipitation of $1130 \mathrm{~mm}$, of which $<10 \%$ is snow. There is inter-annual variation in temperature with the winter months being December-February and the summer months being June-August. The underlying geology of the catchment is granite, with a small schist outcrop. The interfluves above $450 \mathrm{~m}$ are covered by extensive peats ( $<5 \mathrm{~m}$ deep) and peaty podzols $(<1 \mathrm{~m})$. In some places peat is eroded to the mineral interface. Incised catchment slopes have the most freely-draining humus iron podzols ( $<1 \mathrm{~m}$ deep); the main river valley bottoms generally have freely draining alluvial deposits. For a detailed description of the study site and its geology and climate characteristics, see Waldron et al. (2007). 


\subsection{Sampling strategy and calculation of $\mathrm{EpCO}_{2}$}

Samples for measurement of Dissolved Inorganic Carbon (DIC) concentration were collected approximately every $5 \mathrm{~h}$ over a 24-h period and 12 times during June 2003August 2004. The sampling spanned a wide range of flow conditions. DIC $\left(\mathrm{mmol} \mathrm{L}^{-1}\right.$ C) is quantified by direct measurement using a headspace analysis approach (Waldron et al. 2014), to internal precision better than $\pm 0.03 \mathrm{mmol} \mathrm{L}^{-1}$. This was regressed onto discharge, which is measured semi-continuously, to generate a relationship from which DIC is predicted, thus creating a continuous DIC profile (Waldron et al. 2007). The generated relationship between discharge and DIC was indistinguishable from the same relationship constructed 10 years earlier, allowing confidence that this relationship is temporally stable over the constructed 3 years profile. Troll 9000EXP data loggers (In-Situ, Inc.) were used to generate $15 \mathrm{~min}$ frequency time series of temperature, $\mathrm{pH}$ and atmospheric pressure from October 2003 to September 2006. These parameters allowed the excess partial pressure of carbon dioxide $\left(\mathrm{EpCO}_{2}\right)$ to be indirectly calculated from the continuous DIC profile (Waldron et al. 2014). Estimates of the capacity for $\mathrm{CO}_{2}$ efflux, are described as the "Excess partial pressure of $\mathrm{CO}_{2}$ ", $\mathrm{EpCO}_{2}$, a ratio of over-saturation [for more details, see Neal (1998) and Dawson et al. (2009)]. The river system is over-saturated with $\mathrm{CO}_{2}$ with respect to the atmosphere when $\mathrm{EpCO}_{2}$ exceeds 1 . The Troll loggers also generated $15 \mathrm{~min}$ frequency time series of specific conductivity (SC). SC in streams and rivers is influenced by the river geology, in addition to the water flow and temperature (United States Environmental Protection Agency EPA 2012). It is usually higher in low flow periods when the groundwater contribution is proportionally highest (United States Environmental Protection Agency EPA 2012).

\subsection{Statistical analysis and methodology}

The methodology applied here (1) visualizes and explores the $\mathrm{EpCO}_{2}$ variations in the Glen Dye small-order river before, (2) modeling and analyzing the temporal variations and the mechanisms controlling these variations. Approach (1) mainly uses graphical visualization methods and wavelet analysis to identify the temporal fluctuations of $\mathrm{EpCO}_{2}$ and produce primary insights about its relationship with the water hydrology. Approach (2) analyzes and explains the temporal variations of $\mathrm{EpCO}_{2}$ and its relationship to catchment flow (as understood from SC) using additive models. Describing and modeling the various patterns, fluctuations and interactions of $\mathrm{EpCO}_{2}$ are the first step in identifying controls on the concentration.

\subsubsection{Wavelets}

Wavelet analysis is a useful tool for analyzing non-stationary and/or high-frequency time series. Wavelets have the advantage of analyzing a time series by combining both, time and frequency domains. The time series is decomposed into a set of signals which relate to variations or changes at different timescales. The result is a time-scale decomposition of the original signal, which helps identify the cyclical components 
over different frequencies, as well as the long-term trend (Nason 2008; Percival and Walden 2006).

The Discrete Wavelet Transform (DWT) decomposes a time series into discrete scales. The DWT is an orthogonal transform of the equally spaced time series $\left\{X_{t}\right.$ : $t=1, \ldots, N\}$. The vector $\mathbf{W}$ of the DWT coefficients $\left\{W_{n}: n=1, \ldots, N\right\}$ is given by:

$$
\mathbf{W}=\mathbf{R X}
$$

where $\mathbf{X}$ is the time series vector of length $N$ and $\mathbf{R}$ is an $N \times N$ real valued matrix defining the DWT constructed using the chosen filter such that $\mathbf{R}^{T} \mathbf{R}=\mathbf{I}$ (Percival and Walden 2006). Hence, the original signal $\mathbf{X}$ can be reconstructed as follows:

$$
\mathbf{X}=\mathbf{R}^{T} \mathbf{W}=\sum_{j=1}^{J} \mathbf{D}_{j}+\mathbf{S}_{J}
$$

where $J$ is the level of decomposition, $\mathbf{D}_{j}$ is known as the wavelet detail and is associated with changes in the time series at scale $\tau_{j}=2^{j-1}$ and $\mathbf{S}_{J}$ is called the wavelet smooth and is related to variations over scales $\tau_{J+1}=2^{J}$ and higher. The wavelet smooth $\mathbf{S}_{J}$ represents a smooth version of $\mathbf{X}$. This decomposition is known as Multi-Resolution Analysis (MRA). The MRA takes the original signal and distributes it into different signals over the different dyadic scales $\tau_{j}=2^{j-1}, j=1, \ldots, J$ without losing the original available information, then analyzes each component with a resolution matched to its scale (Percival and Walden 2006).

The Maximum Overlap Discrete Wavelet Transform (MODWT) is a modified version of the DWT which similarly decomposes the time series into a set of wavelet details plus a smooth component. The MODWT has some advantages over the DWT: first, it does not have any restrictions on the series length (i.e., $N$ is not necessarily a power of two); second, the MODWT coefficients and associated MRA are not affected by the choice of the starting point of the time series. The trade-off of these advantages is loss of orthogonality and higher computational cost (Percival and Walden 2006). The MRA is useful in identifying the major timescale contributor to the variability in the time series. The estimated wavelet variance at a particular scale $\tau_{j}, \hat{v}_{X}\left(\tau_{j}\right)$, which determines the contribution of that timescale to the variability in the original signal is given by:

$$
\hat{v}_{X}\left(\tau_{j}\right)=\frac{1}{M_{j}} \sum_{t=L_{j}-1}^{N-1} W_{j, t}^{2}
$$

where $L_{j}=\left(2^{j}-1\right)(L-1)-1$ such that $L$ is the filter width, $M_{j}=N-L_{j}+1$ is the number of coefficients not affected by the boundary conditions which guarantees the unbiasedness of the estimator and $W_{j, t}$ are the wavelet coefficients at scale $j$ and time $t$ (Percival and Walden 2006).

Here, the MODWT based on least asymmetric filter of width equal to 8, $\mathrm{LA}(8)$, is applied to the $\mathrm{EpCO}_{2}$ and the associated hydrological variables series. Least asymmetric (LA) filters are a special class of the Daubechies filters. The phase function of LA filters is very close to that of a linear phase filter, thus making it easy to line up 
features in the filtered series with the original series (Percival and Walden 2006). The LA filter is then appropriate since it is of interest to align events in time. A filter width equal to 8 provides a good smooth representation of the corresponding time series and is chosen after comparing a series of wavelet transforms obtained for a range of filter width values. The wavelet transform corresponding to smaller filter width values resulted in sharp peaks in the individual elements of the time series decomposition, and greater width values did not make any difference. The wmt sa $\mathrm{R}$ package developed for wavelet analysis by Constantine and Percival in 2013 is used to obtain the MRA of the studied time series via the MODWT of the corresponding series. The wavelet transform cannot be applied to time series with missing data. Hence, the missing values are first imputed using linear interpolation. The interpolation is done separately for each month and for each time within the month to better reproduce the variability of the series.

\subsubsection{Additive modeling}

Additive models are flexible tools for describing and visualizing non-linear and nonparametric effects of explanatory variables $X_{k}$ on a response variable of interest $Y$, without specifying a particular form for the regression function [see, for example, Hastie and Tibshirani (1990), Bowman and Azzalini (1997)]. An additive model has the following structure:

$$
Y_{t}=\beta_{o}+f_{1}\left(X_{1 t}\right)+f_{2}\left(X_{2 t}\right)+f_{3}\left(X_{3 t}, X_{4 t}\right)+\cdots+\varepsilon_{t}
$$

where the observations $Y_{t}, t=1, \ldots, n$ are assumed to be independent with means $E\left(Y_{t}\right)=\mu_{t}, f_{j}$ are smooth functions of covariates $X_{k}$ whose shapes are unrestricted and need to be estimated and the error term $\varepsilon_{t}$ denotes an independent normally distributed random variable with mean 0 and variance $\sigma^{2}$. Hence, the distribution of $Y_{t}$ is also assumed Gaussian. Here, the univariate smooth functions are approximated by cubic regression splines, except for the periodic effects which are estimated using cyclic cubic regression splines, and the bivariate smooth functions are represented by tensor product splines. Tensor product splines are invariant to linear scaling of covariates and are good to smooth interactions of quantities measured in different units (Wood 2006). The smoothness of each curve $f_{j}$ is controlled by a smoothing parameter. The basis dimension of each smooth function is set based on the Akaike Information Criteria (AIC) to identify a smooth interpretable relationship. Then, the appropriate smoothing parameter of each smooth curve is selected automatically using the restricted maximum likelihood criteria. Likelihood methods tend to be more robust for smoothing parameter selection (Wood 2011). Model variable selection is performed using AIC and approximate $F$-tests. The mgcv package (Wood 2006) supplied with R for fitting Generalized Additive Models (GAMs) is used. A GAM is a generalization of the additive model for non-Gaussian error distributions. Additive models are fitted using the fitting routine bam, assuming a Gaussian distribution for the errors, which is a computationally efficient alternative for the main routine gam for very large data sets (Wood et al. 2015). For detailed discussion on splines and GAMs, see Wood (2006). 
The errors $\varepsilon_{t}$ in Eq. 4 are assumed mutually independent, whereas autocorrelation is one of the characteristics of hydrological time series. The additive models only describe how the response variable is statistically related to the explanatory variables without accounting for the dependence of the response on its past values. Failure to account for autocorrelation appropriately may result in an underestimate of the standard errors for the estimated smooth curves, which makes the estimates inefficient and the inference about the estimates unreliable. One solution is a two-stage fitting procedure (TSP). The first stage involves fitting a GAM assuming independent distributed errors, and the second entails fitting an appropriate correlation structure to the residuals of the fitted GAM. An estimate for the correlation matrix of the residuals $\varepsilon_{t}, \hat{\mathbf{V}}$, can be obtained from the data based on a specified correlation structure. Each smooth function of the additive model has an estimate of the form $\hat{f}_{j}=\mathbf{S}_{j} \mathbf{y}$, where $\mathbf{S}_{j}$ is the smoothing matrix of component $j$ and the standard errors are readily available as the square root of the diagonal entries $\mathbf{S}_{j} \hat{\mathbf{V}} \mathbf{S}_{j}^{T} \sigma^{2}$. The error variance $\sigma^{2}$ can be estimated from the $R S S=\mathbf{y}^{T}(\mathbf{I}-\mathbf{S})^{T}(\mathbf{I}-\mathbf{S}) \mathbf{y}$ and the approximate degrees of freedom associated with error is given by $\operatorname{tr}\left\{(\mathbf{I}-\mathbf{S})^{T}(\mathbf{I}-\mathbf{S}) \mathbf{V}\right\}$. Then, the variability bands ( \pm 2 S.E.) of the estimated smooth curves can be adjusted based on the new standard errors (Bowman et al. 2009). An alternative to this two-stage procedure will be presented in the discussion.

\section{Results}

In this section, we first present the initial exploratory data analysis (EDA) and wavelets analysis results. Then, we show the results of the additive models used to analyze the variations in $\mathrm{EpCO}_{2}$ at the daily, monthly and yearly timescales.

\subsection{Exploratory data analysis (EDA) and wavelets}

Figure 1 displays the calculated $\mathrm{EpCO}_{2}$ series and the recorded measurements of discharge, temperature, $\mathrm{pH}$ and SC from 1st October 2003 to 30th September 2006, spanning 3 full hydrological years. Each hydrological year runs from October to September and hereafter is abbreviated as HY. The $\mathrm{EpCO}_{2}$ exhibits temporal variability and varies between 0.26 and 10 . The average $\mathrm{EpCO}_{2}$ over the whole study period is $2.57 \pm 1.01$. Thus, our sample point on the Water of Charr is, on average, oversaturated with $\mathrm{CO}_{2}$. Similarly, water discharge is variable, with an average of $1.1 \pm$ $4.5 \mathrm{~m}^{3 / \mathrm{s}}$ through the whole study period. Comparison of discharge between HYs shows that HY2003/2004 had the wettest summer, HY2004/2005 had the driest winter and HY2005/2006 was the wettest overall (Table 1). The coldest months in the 3 hydrological years are December-February (Fig. 1) with an average water temperature of $2.9 \pm 1.7^{\circ} \mathrm{C}$; the warmest months are June-August with an average temperature of $14 \pm 2.8^{\circ} \mathrm{C}$.

Figure 2 illustrates the seasonal and diurnal responses in $\mathrm{EpCO}_{2}$ in each of the HYs. The median $\mathrm{EpCO}_{2}$ (represented by the black bar in the middle of each box) is generally higher in summer (June-August) than winter (December-February). EpCO $\mathrm{CO}_{2}$ 


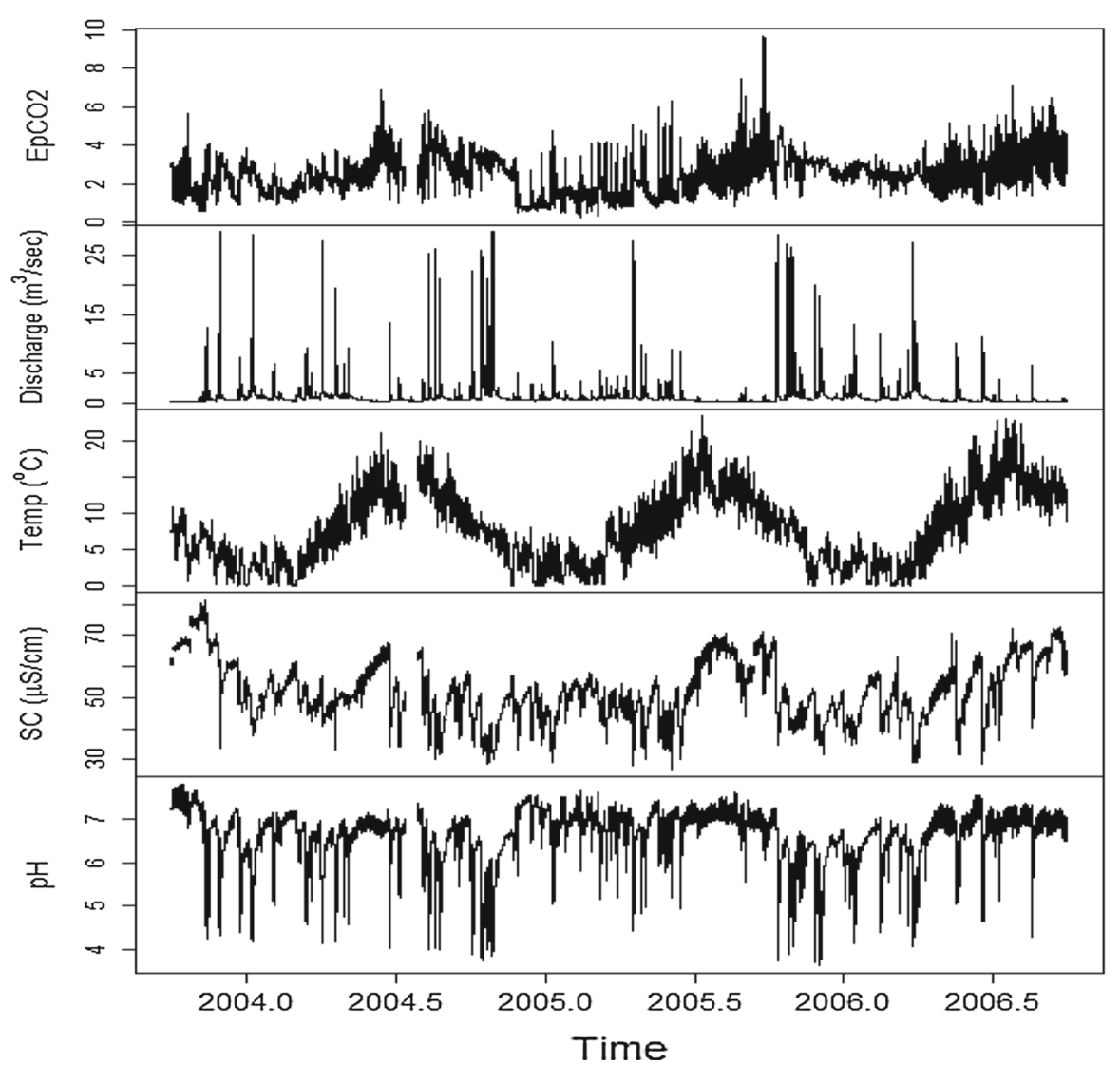

Fig. 1 Time plots of the $15 \mathrm{~min}$ frequency series of the $\mathrm{EpCO}_{2}$, flow, temperature, $\mathrm{pH}$ and $\mathrm{SC}$ series from October 2003 to September 2006

Table 1 Total water discharge at the water of Charr sampling point across the winter (December-February) and summer (June-August) of each HY and the whole HY

\begin{tabular}{lcll}
\hline HY & \multicolumn{2}{l}{ Discharge $\left(\mathrm{m}^{3 / \mathrm{s}}\right)$} & \\
\cline { 2 - 4 } & Winter & Summer & Overall \\
\hline HY2003/2004 & 10,083 & 8882 & 37,063 \\
HY2004/2005 & 6496 & 3880 & 35,958 \\
HY2005/2006 & 12,385 & 3726 & 40,044
\end{tabular}

is also more variable during summer. The hourly boxplots show that the median $\mathrm{EpCO}_{2}$ is smallest close to midday and largest just after midnight and that $\mathrm{EpCO}_{2}$ exhibits more variability during darkness.

The EDA shows inter-annual and intra-annual variations in the $\mathrm{EpCO}_{2}$ and the other hydrological variables, showing the time series to be non-stationary. Animated 3-D plots, available in the supplementary material, provide a better representation of the interactions between the $\mathrm{EpCO}_{2}$ and the variables describing the water hydrology. 

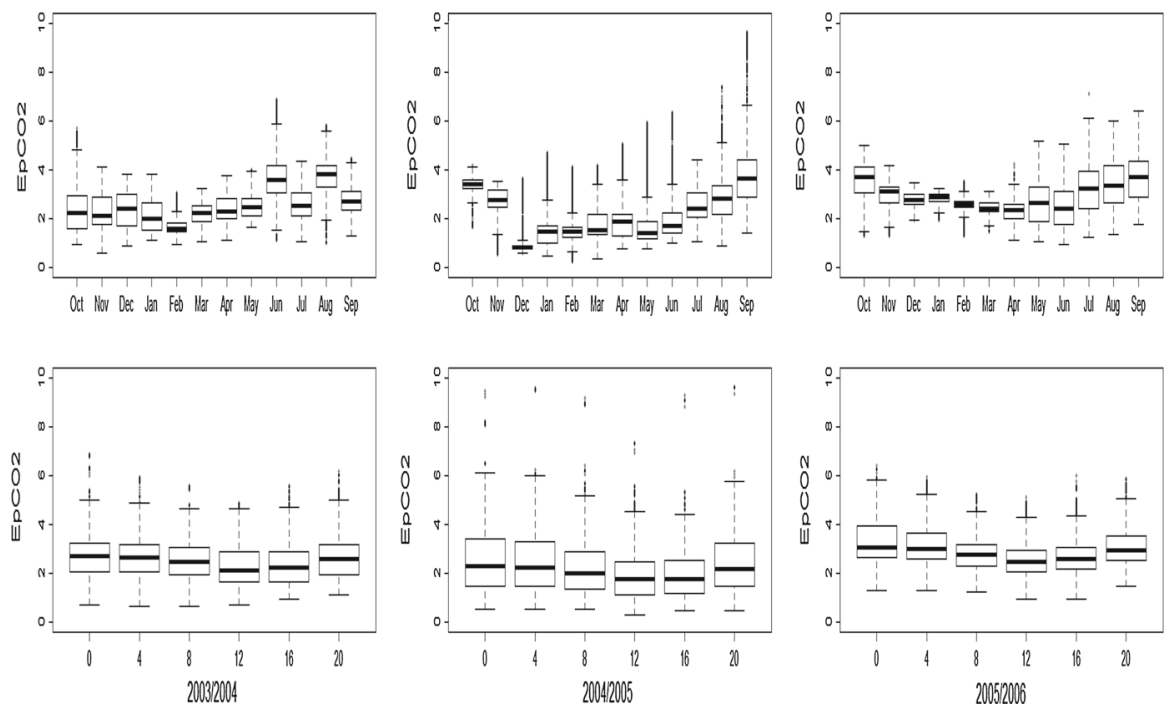

Fig. $2 \mathrm{EpCO}_{2}$ in each Month (top) and Hour (bottom) in the hydrological years 2003/2004 (left), 2004/2005 (middle) and 2005/2006 (right)

The $\mathrm{EpCO}_{2}$ is highly dynamic and the hydrodynamics might also contribute to the $\mathrm{EpCO}_{2}$ variability, e.g., discharge events are sometimes associated with a particular feature in the $\mathrm{EpCO}_{2}$ series. However, the response of $\mathrm{EpCO}_{2}$ to flow events may differ depending on preceding events and differences in summer and winter biological productivity. In conclusion, it is not easy to draw interpretable conclusions for such complex hydrological high-frequency data using simple exploratory methods. One way to better visualize and analyze the temporal variations of these HHFD in the time-frequency domain is to use wavelet analysis.

There are some periods of missing data (Fig. 1). The $\mathrm{EpCO}_{2}$ series in 2003/2004 has 1544 missing values in total, one in February 2004 and the rest in July 2004 (see the top panel of Fig. 1), which represent $4.4 \%$ of the total record. Each of the $\mathrm{pH}$, temperature, and SC series of 2003/2004 and 2004/2005 has less than 5\% missing values of the total record. All the missing values are imputed as mentioned earlier before starting the wavelet analysis. These imputed values are shown in grey in Fig. 3.

The MODWT with LA(8) filter decomposes the $\mathrm{EpCO}_{2}$ series for each of the hydrological years into 12 wavelet details and one smooth component $\left(\mathbf{X}=\sum_{j=1}^{12} \mathbf{D}_{j}+\mathbf{S}_{12}\right)$, where 12 is the maximum number of scales. The wavelet details $\left(\mathbf{D}_{j}, j=1, \ldots, 12\right)$ reflect changes in the original series over scales of $15\left(2^{j-1}\right)$ minutes and the smooth component $\left(\mathbf{S}_{12}\right)$ relates to variations over about 44 days and higher representing the overall trend. The MRA of the $\mathrm{EpCO}_{2}$ series (Fig. 3 for $\mathbf{D}_{1}, \mathbf{D}_{6}$ and $\mathbf{D}_{12}$ ), represents changes in the original series on a scale of $15 \mathrm{~min}, 8 \mathrm{~h}$ and $\sim 22$ days, respectively. The MRA indicated that the detail components $\mathbf{D}_{j}, j=1, \ldots, 4$ (only $\mathbf{D}_{1}$ is shown here due to space limitations) are the least variable reflecting the small scales variability and can be related to weather or hydrological events. Therefore, these high-frequency scales capture the uncommon $\mathrm{EpCO}_{2}$ levels which might be influenced by short-lived 


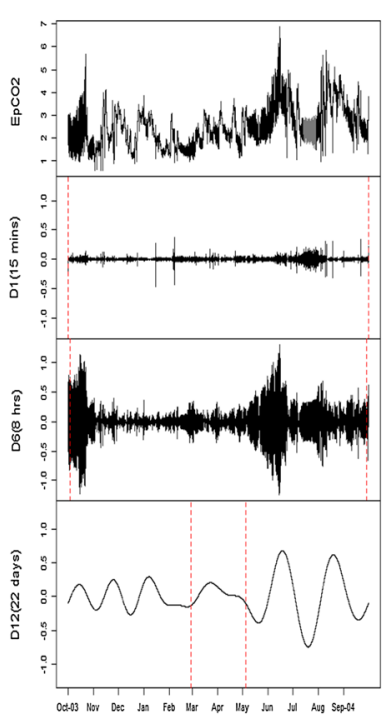

20032004 (IIme)
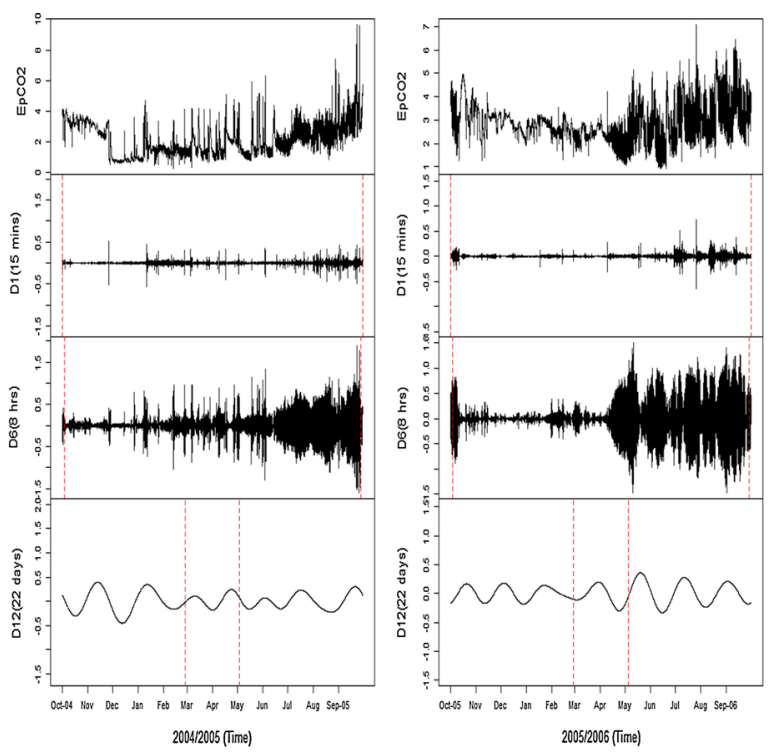

Fig. 3 Multi-resolution analysis of $\mathrm{EpCO}_{2}$ series for the hydrological years 2003/2004 (left), 2004/2005 (middle) and 2005/2006 (right). The wavelet details $\mathbf{D}_{1}(15 \mathrm{~min}), \mathbf{D}_{6}(8 \mathrm{~h})$ and $\mathbf{D}_{12}(\sim 22$ days) are on the same scale, different from the original series (top). The dashed vertical lines indicate the areas that might be affected by boundary coefficients
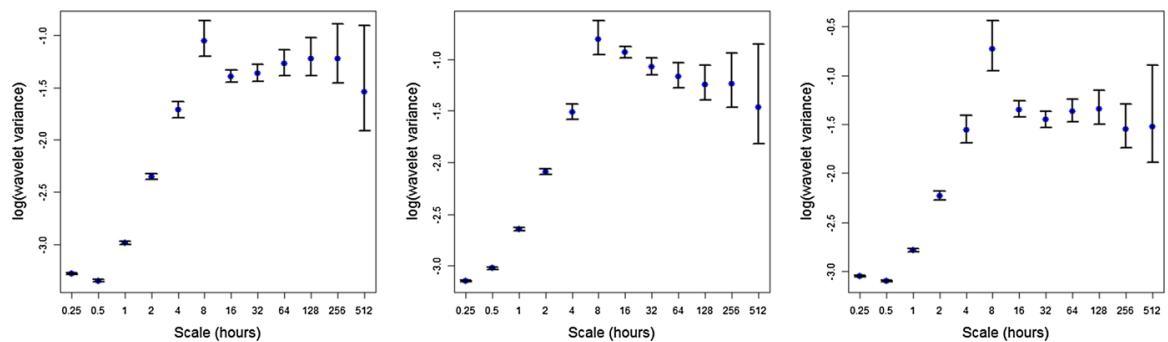

Fig. 4 Wavelet variance of the $\mathrm{EpCO}_{2}$ series of the hydrological years 2003/2004 (left), 2004/2005 (middle) and $2005 / 2006$ (right) for the scales $15\left(2^{j-1}\right), j=1, \ldots, 12$

changes in the water hydrology such as intense periods of rainfall. $\mathbf{D}_{6}$ is the main contributor to the sample variance of the $\mathrm{EpCO}_{2}$ (see Fig. 4) and the associated temperature series reflecting the presence of an intra-daily cycle. This seems reasonable since changes over a scale of $8 \mathrm{~h}$ correspond to the daylight cycle. However, this diel cycle is not constant throughout each hydrological year but larger fluctuations are rather observed during summer. This MRA also shows that the $\mathrm{EpCO}_{2}$ of the dry summer of HY2005/2006 exhibits this diel pattern clearly for a longer time period compared to the wetter summers of HY2003/2004 and HY2004/2005. The wavelet detail $\mathbf{D}_{12}$ can be seen as an approximation for the monthly variations since it reflects changes over nearly 22 days. 

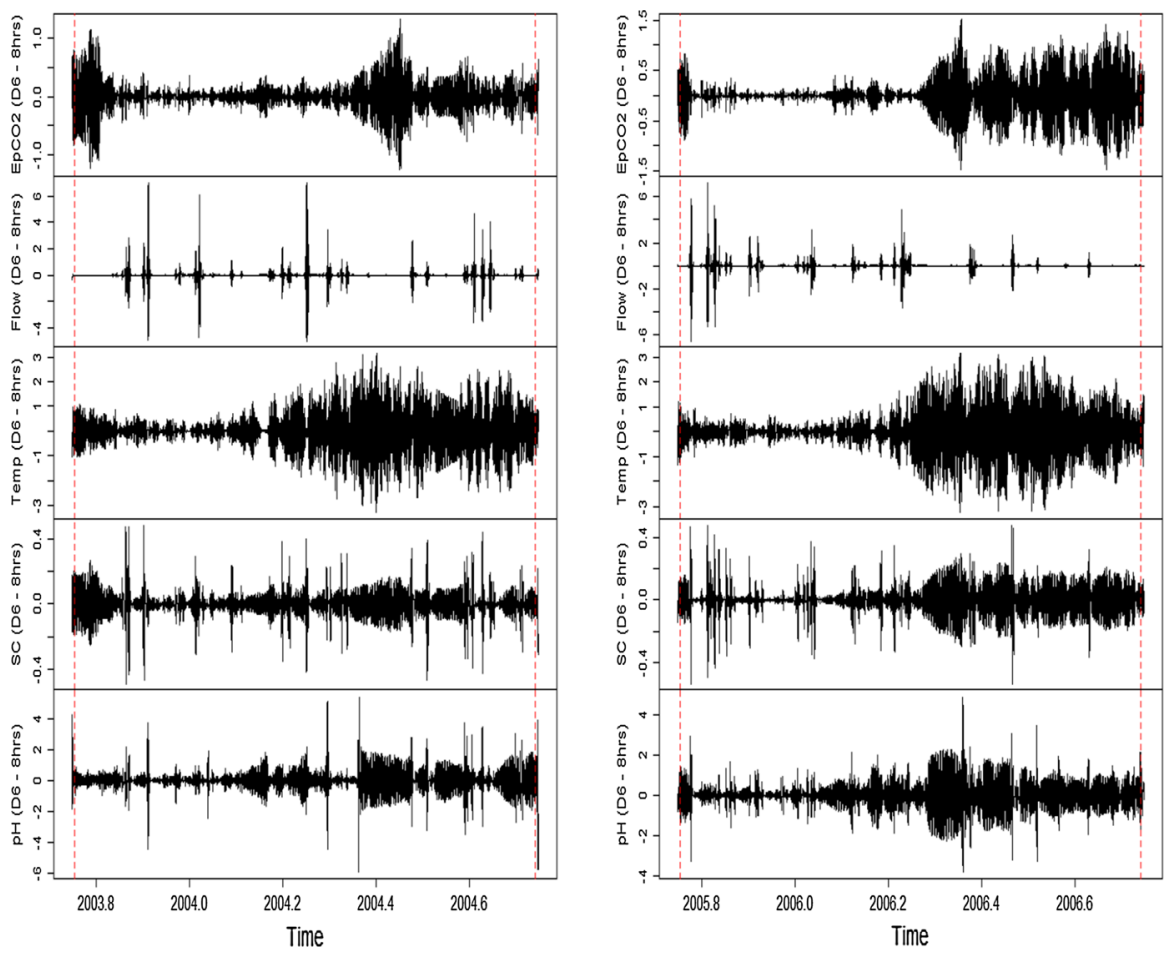

Fig. 5 6th wavelet detail ( $8 \mathrm{~h}$ scale) of $\mathrm{MRA}$ of $\mathrm{EpCO}_{2}$ (top), flow, temperature, $\mathrm{SC}$ and $\mathrm{pH}$ (bottom) for the hydrological years 2003/2004 (left) and 2005/2006 (right). The dashed vertical lines indicate the areas that might be affected by boundary coefficients

Figure 5 compares the 6th wavelet detail series, representing the changes over a scale of $8 \mathrm{~h}$, for the different hydrological variables with the $\mathrm{EpCO}_{2}$ series. The timing, extent and number of occurrences of hydrological events differ from one hydrological year to another. The highest $\mathrm{EpCO}_{2}$ variability is usually associated with little changes in discharge, consistent with internal fluvial carbon cycling, while hydrological events are associated with compressed $\mathrm{EpCO}_{2}$ variability. The periods when $\mathrm{pH}$ and $\mathrm{SC}$ show most change occur with flow events. The variability in $\mathrm{EpCO}_{2}$ evolves coherently with the variability in temperature, in itself a proxy for seasonality: $\mathrm{EpCO}_{2}$ appears to be more variable during summer when there are larger fluctuations between day and night temperatures. The changes in temperature and discharge influence the SC and $\mathrm{pH}$, which in turn influence the $\mathrm{EpCO}_{2}$ across the different years.

The EDA and wavelet analysis highlighted the seasonal and diurnal fluctuations of $\mathrm{EpCO}_{2}$ and the differences in these variations between the individual hydrological years. They also revealed that the hydrodynamics contribute to part of the $\mathrm{EpCO}_{2}$ variability although the nature of these relationships is very complex and difficult to explore and visualize through exploratory tools. It is not clear from the exploratory analysis whether or not the temporal patterns in $\mathrm{EpCO}_{2}$ can be described entirely by hydrology. In addition, the EDA cannot highlight the persistent temporal correla- 
tion between the $15 \mathrm{~min}$ frequency measurements after we account for the temporal dynamics. Therefore, a set of hierarchical additive models are fitted at different temporal scales to better describe and analyze the variations in $\mathrm{EpCO}_{2}$ at these timescales.

\subsection{Additive models}

Initially, additive models are developed for individual days followed by individual months and finally for each hydrological year separately. These additive models are useful in explaining the variations in $\mathrm{EpCO}_{2}$ and studying the relationship between $\mathrm{EpCO}_{2}$ and the available physiochemical catchment variables, which are not used in deriving the $\mathrm{EpCO}_{2}$ (i.e., SC), within a day, a month and a hydrological year. They also describe the differences in variations between the different days, months and hydrological years. This temporal hierarchy better shows the changes and the increased complexity of (1) the processes driving $\mathrm{EpCO}_{2}$, (2) the multivariate interactions between $\mathrm{EpCO}_{2}$, water hydrology and time components, and (3) the temporal correlation structures from the daily to the yearly timescales.

\subsubsection{Daily additive models}

It is evident from the previous EDA and MRA that the $\mathrm{EpCO}_{2}$ exhibits a diel cycle with altering magnitude and pattern from one day to another. These alterations could be attributed to seasonal changes or other hydrological conditions. Let $Y_{t}$ denote the $\mathrm{EpCO}_{2}$ at time point $t$, and $\mathbf{X}_{t}=\left(X_{t}^{\text {Time within day }}, X_{t}^{\text {Hour of day }}, X_{t}^{\mathrm{SC}}\right)$ be the vector of explanatory variables at time $t$, where $X_{t}^{\text {Time within day }}$ is a continuous variable representing the time within day at which the measurement is recorded, $X_{t}^{\text {Hour of day }}$ is an index of the hour within day and $X_{t}^{\mathrm{SC}}$ is the measured SC at time $t$. Then, the daily variations of $\mathrm{EpCO}_{2}$ are described through the following additive model:

$$
Y_{t}=f_{1}\left(X_{t}^{\text {Time within day }}\right)+f_{2}\left(X_{t}^{\mathrm{SC}}\right)+f_{3}\left(X_{t}^{\text {Hour of day }}, X_{t}^{\mathrm{SC}}\right)+\varepsilon_{t}
$$

where the smooth functions $f_{j}, j=1,2,3$, capture the daily cycle, the main effect of SC and the bivariate effect of hour within day and $\mathrm{SC}$ on $\mathrm{EpCO}_{2}$, respectively; and $\varepsilon_{t}$ accounts for the random effects not explained by the additive model. The functions $f_{1}$ and $f_{2}$ are represented using cubic regression splines and $f_{3}$ using a tensor product of two cubic regression splines, as described in Sect. 2.3.2. The model is fitted to the data of some selected days. The model assumptions, including independence of the errors, are shown to be all valid. The estimated additive model explains about $99 \%$ deviance of the data of each selected day.

Figure 6 shows only the results of 14/10/2005, 14/1/2006, 14/4/2006 and 14/7/2006. As can be seen, the fitted splines capture the response of $\mathrm{EpCO}_{2}$ to time within day reflecting changes in the biological activity according to the daylight cycle. This intradaily cycle of $\mathrm{EpCO}_{2}$ changes from one day to another, according to the seasonal and hydrological conditions and is significantly stronger in the summer days. It is also clear that the relationship between $\mathrm{EpCO}_{2}$ and $\mathrm{SC}$ is significantly changing with hour 

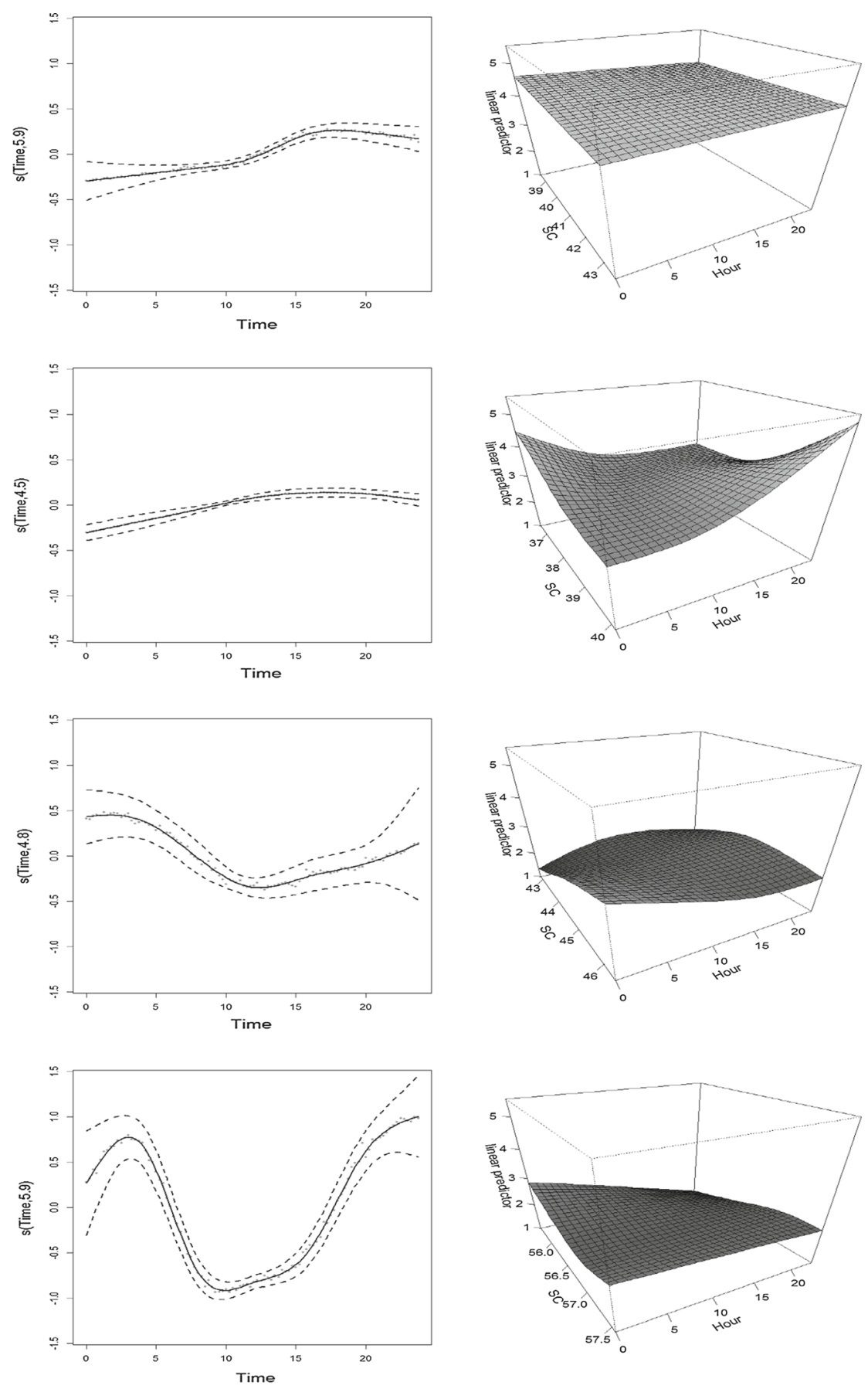

Fig. 6 The fitted smooth functions of Time (left) and the interaction between SC and Hour of day (right) of the daily GAM for the days 14/10/2005 (top), 14/1/2006, 14/4/2006 and 14/7/2006 (bottom). The dashed lines in the left panels are the \pm 2 S.E. bands 
and day, justifying the multivariate interactions between $\mathrm{EpCO}_{2}$, hydrodynamics and time.

\subsubsection{Monthly additive models}

The EDA has identified seasonal differences in the behavior and fluctuations of $\mathrm{EpCO}_{2}$. These monthly/seasonal variations are explained via fitting the following additive model for each month of the hydrological year separately:

$$
\begin{aligned}
Y_{t}= & f_{1}\left(X_{t}^{\text {Time within month }}\right)+f_{2}\left(X_{t}^{\text {Hour of day }}, X_{t}^{\mathrm{SC}}\right) \\
& +f_{3}\left(X_{t}^{\text {Hour of day }}, X_{t}^{\text {Day of month }}\right)+f_{4}\left(X_{t}^{\text {Day of month }}, X_{t}^{\mathrm{SC}}\right)+\varepsilon_{t}
\end{aligned}
$$

where $X_{t}^{\text {Time within month }}$ is a continuous variable denoting the time within each month; $f_{1}$ determines the main behavior of $\mathrm{EpCO}_{2}$ within each studied month; and $f_{2}$ describes the bivariate effect of hour within day and SC. Based on the results of the daily additive models, the smooth functions $f_{3}$ and $f_{4}$ are added to the model to capture the changing effects of hour within day and SC from day to day, respectively. $f_{1}$ is approximated using cubic regression splines; and $f_{j}, j=2,3,4$, are represented by tensor product splines.

Only the model results of January and June 2005 are presented due to space limitations. The estimated additive models explain 72 and $91 \%$ deviance of the data in January and June, respectively. However, the ACF of the model residuals shows a slowly decaying correlation structure in January, and not only significant correlations at high lags, but a remaining periodic pattern every $24 \mathrm{~h}$ that is not captured by the model in June. These dependence structures affect the efficiency of the estimates and make the inference procedure unreliable. In January, the estimated additive model residuals are modeled via an autoregressive process of order 1 (AR(1)), which has accounted for the remaining dependence. In June, a greater degree of structure was displayed in the residuals after fitting the additive model.

AIC indicates that an AR of order $32(8 \mathrm{~h})$, on average, is sufficient to account for this periodic dependence structure left in the residuals of the summer months. The AR order selected by the AIC coincides with the length of the dominant intra-daily cycle identified by the wavelet analysis. Nevertheless, $\mathrm{EpCO}_{2}$ seems to heavily depend, in particular, on its preceding 2-h measurements. Therefore, cubic regression splines of the 2- and 8-h lagged dependent variables are added to the model. The 2-h lag denotes the average extent of short-term dependence, while the 8-h lag represents the extent of long-term dependence. The 2- and 8-h lagged $\mathrm{EpCO}_{2}$ account for the long range dependence and the periodic dependence structure and any remaining autocorrelation is accounted for via an $\mathrm{AR}(1)$ process fitted to the residuals of the adjusted model.

The monthly additive models indicate that the $\mathrm{EpCO}_{2}$ dynamics vary across the different months of the hydrological year. Figure 7 illustrates the clear dissimilarities in the trend, variability of $\mathrm{EpCO}_{2}$ and interactions with time and water hydrology between January and June. It is evident that the $\mathrm{EpCO}_{2}$ is more variable in June. Figure 7 shows evidence of the intra-daily cycle in June and its absence in January. 

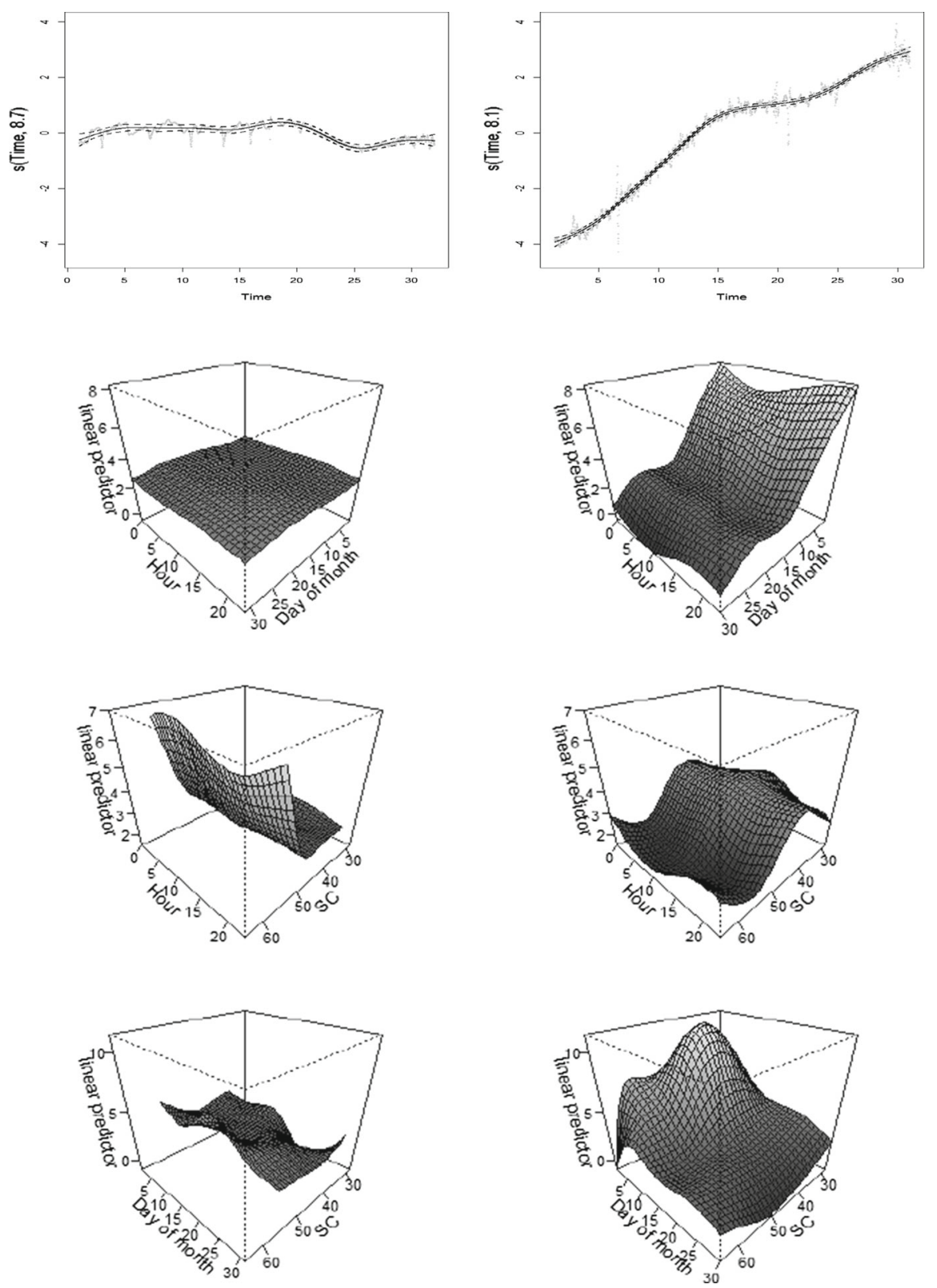

Fig. 7 The fitted smooth functions of Time (top) and the interactions: Hour of Day and Day of month; Hour of Day and SC; and Day of month and SC (bottom) of the monthly GAM for January (left) and June (right) 2005. The dashed lines in the top panels are the adjusted \pm 2 S.E. intervals after accounting for the autocorrelation present in the residuals $\varepsilon_{t}$ 
The $\mathrm{EpCO}_{2}$ and the magnitude of its diel cycle changes significantly from one day to another within June. The figure also indicates that the daylight cycle in June has a greater significant influence on the fluctuations of $\mathrm{EpCO}_{2}$ than water hydrology during the absence of hydrological events (at high SC). Conversely, water hydrology dampens the diel cycle and dominates these fluctuations at periods of hydrological events. In January, $\mathrm{EpCO}_{2}$ does not seem to exhibit an intra-daily cycle and variations are mostly attributed to hydrodynamics.

Generally, both time and hydrology contribute to the variations in $\mathrm{EpCO}_{2}$. However, the contribution of the temporal patterns and hydrology is time-dependent and changes from one season to another. Also, the temporal correlation remaining between the residuals after accounting for these variations changes seasonally and shows more complex structures in summer. It is evident that this temporal autocorrelation is more persistent when the model is extended to cover a longer time period.

\subsubsection{Yearly additive models}

The monthly additive models illustrated intra-annual variations in $\mathrm{EpCO}_{2}$. However, the EDA indicated the non-stationarity of the full time series and the presence of interannual variations, as a result of the different climatological conditions characterizing each HY. Therefore, the model is extended to describe the variations in $\mathrm{EpCO}_{2}$ within each HY separately and highlight the differences between the 3 hydrological years. As the model covers a longer time period, the autocorrelation structure becomes more difficult to model. Hence, the yearly variations of $\mathrm{EpCO}_{2}$ are described through the following TSP:

$$
\begin{aligned}
Y_{t}= & f_{1}\left(X_{t}^{\text {Time within year }}\right)+f_{2}\left(X_{t}^{\text {Hour of day }}, X_{t}^{\text {Day of year }}\right) \\
& +f_{3}\left(X_{t}^{\text {Hour of day }}, X_{t}^{\text {SC }}\right) \\
& +f_{4}\left(X_{t}^{\text {Day of year }}, X_{t}^{\mathrm{SC}}\right)+f_{5}\left(Y_{t-8}\right)+f_{6}\left(Y_{t-32}\right)+\varepsilon_{t} \\
\varepsilon_{t}= & \phi \varepsilon_{t-1}+\xi_{t}
\end{aligned}
$$

where $X_{t}^{\text {Time within year }}$ denotes a continuous variable representing the time within the year used to reflect the yearly trend; and $Y_{t-8}$ and $Y_{t-32}$ denote the 2- and 8-h lagged $\mathrm{EpCO}_{2}$, respectively, which were successful in accounting for the persistent periodic dependence structure in the monthly models. The smooth function $f_{1}$ captures the global trend of $\mathrm{EpCO}_{2}$ along each hydrological year; $f_{2}$ describes the changing effect of the daily cycle from day to day; $f_{3}$ and $f_{4}$ explain the bivariate effect of SC with hour and day of year, respectively; and $f_{5}$ and $f_{6}$ capture the effect of the 2- and 8-h lagged $\mathrm{EpCO}_{2}$ on the current $\mathrm{EpCO}_{2}$, respectively. As previous, $f_{j}, j=1,5,6$ is represented by cubic regression splines and $f_{j}, j=2,3,4$ by tensor product splines. The residuals $\varepsilon_{t}$ in Eq. 7 follow an AR(1) (see Eq. 8), where $\phi$ is known as the autoregressive parameter and $\xi_{t}$ is a white noise process with mean 0 and variance $\sigma_{\xi}^{2}$. 
The fitted additive models explain about $95 \%$ of the variability in $\mathrm{EpCO}_{2}$ in each hydrological year. It is evident that the diel cycle is dominating the changes in $\mathrm{EpCO}_{2}$ at high SC levels (Fig. 8) i.e., at low flow when in-stream biological processes are most dominant. By incorporating lagged dependent variables in the model, $\mathrm{EpCO}_{2}$ for the 3 years exhibits the same patterns but with different magnitude. The autocorrelation in the residuals has been substantially reduced after adding the lagged $\mathrm{EpCO}_{2}$ to the additive model and modeling the residuals via an AR process. However, a little periodic structure is still evident.

In brief, it is evident that the processes controlling the $\mathrm{EpCO}_{2}$ are time and scale dependent. The multivariate relationships between the $\mathrm{EpCO}_{2}$, water hydrology and time components change from one scale to another and become more complex when the model is extended to describe a longer time period within the hydrological year. In addition, the autocorrelation structure between the residuals remaining after accounting for the temporal and water hydrological changes with time and becomes more persistent and composite at the yearly scale. Therefore, lagged variables and more multivariate interactions are added to explain the increased variability and account for the persistence of temporal correlations at the larger timescales.

\section{Discussion and conclusion}

It is evident that although hydrological high-frequency data involve previously inaccessible information, they pose various challenges to statistical modeling and analysis. We evidence this here using an illustrative dataset of high-resolution time series of $\mathrm{EpCO}_{2}$. Exploring and modeling these high-resolution sensor data was very complex and challenging because of the differences in the behavior of the variable of interest over the different timescales, the complex multivariate relationships which are time and scale dependent and the persistent temporal correlation characterizing such hydrological high-frequency data.

The primary EDA showed that $\mathrm{EpCO}_{2}$ is non-stationary and exhibits variations over a wide range of timescales. $\mathrm{EpCO}_{2}$ is generally higher in summer than winter and more variable during summer due to the greater catchment productivity in summer when more $\mathrm{CO}_{2}$, or sources of, are available, and greater in-stream processing of $\mathrm{C}$ results in $\mathrm{CO}_{2}$ consumption (during day-time) and production (during night-time). This processing can be seen in the intra-daily cycle of $\mathrm{EpCO}_{2}$, which is lowest close to midday (maximum solar radiation to support photosynthesis) and highest just after midnight, when respiration has occurred for longest and hence $\mathrm{CO}_{2}$ concentration is highest.

Wavelet analysis helped identify temporal variability, including intra-daily, seasonal and inter-annual variations. These variations arise due to changes in the relative strength of external (e.g., climatological) and internal (biological processing) drivers of resultant $\mathrm{EpCO}_{2}$. The MRA indicated that the intra-daily cycle is the major contributor to the variability of the $\mathrm{EpCO}_{2}$ series. This intra-daily cycle reflects the dark-light-dark cycle within the day. The amplitude of this diel cycle is not constant throughout the year but larger variability occurs during summer when a pronounced diurnal cycle is present. It is also evident that the variability resulting from the daylight cycle changes 
Fig. 8 The fitted smooth surfaces of the interaction between SC and Hour of day of the yearly GAM for HY2003/2004 (top), HY2004/2005 and HY2005/2006 (bottom)
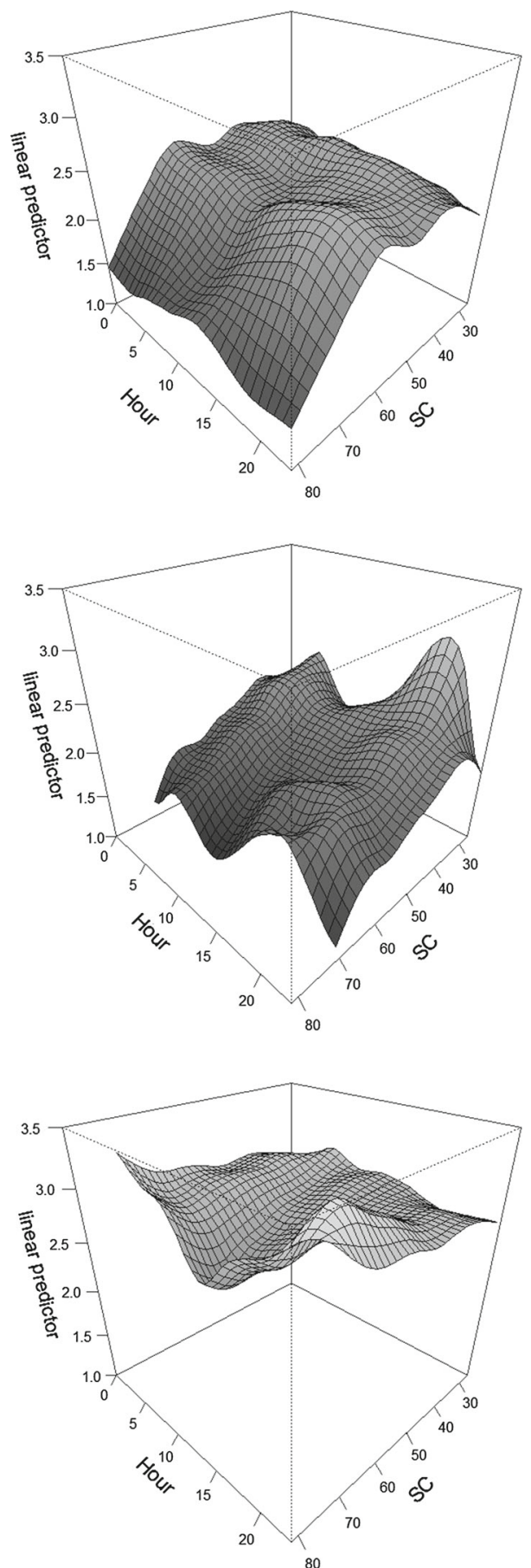
from one year to another, again reflecting different balances of external and internal drivers of $\mathrm{EpCO}_{2}$.

The hierarchical additive models fitted over a day, a month and a year showed that the variability of $\mathrm{EpCO}_{2}$ and its relationship with water hydrology are time and scale dependent. The additive models allow the temporal variations and the mechanisms controlling $\mathrm{EpCO}_{2}$ across the different timescales to be accommodated. These temporal variations and multivariate relationships change across the different timescales and become more complex as the model is extended to cover a longer time period within the hydrological year. These additive models showed that the $\mathrm{EpCO}_{2}$ exhibits a 24-h dark-light-dark cycle reaching the minimum value at noon. The magnitude of this day/night cycle changes along the year and is more apparent during summer where the $\mathrm{EpCO}_{2}$ reaches its maximum levels. It was also obvious that the hydrology has an influence on the level of $\mathrm{EpCO}_{2}$. At low flow, DIC concentration is highest (Waldron et al. 2007) and biological activity is greatest (as temperature tends to be higher); event flow, whilst flushing out soil $\mathrm{CO}_{2}$ so increasing the pool size, ultimately dilutes the DIC pool and so lowers saturation of dissolved carbon dioxide. Turbulent waters and colder temperatures reduce biological activity. As such $\mathrm{CO}_{2}$ over-saturation is reduced and $\mathrm{EpCO}_{2}$ decreases. The diel cycle can still exist, but variability is reduced in winter. Seasonality in flow thus has a significant effect on the $\mathrm{EpCO}_{2}$. The diel cycle appears to dominate the $\mathrm{EpCO}_{2}$ variations in summer during the absence of hydrological events and during low flows (evidenced by higher SC), while high flow events dampen the diel cycle in winter. Hence, the contribution of the temporal and hydrological variations changes with season and timescale. Consequently, the fitted additive models encountered some problems in uniquely identifying the sources of variability and the contribution of each variable to the variability in $\mathrm{EpCO}_{2}$.

Serial autocorrelation is one of the characteristics of high-resolution time series. The residuals of the fitted additive models displayed a periodic autocorrelation structure that persists over a large number of lags. The complexity of the dependence structure increases from daily to yearly timescales. Therefore, modeling these HHFD by assuming independence is no longer valid. A two-stage fitting procedure has been used here, where some lagged dependent variables are added to the model; then an AR process is fitted to the adjusted model residuals. An alternative method would be to incorporate the correlation structure through fitting a generalized additive mixed model (GAMM) using the gamm function in the mgcv library in R (Wood 2006). The GAMM simultaneously fits a GAM - or an additive model as a special case if the errors are assumed to be normally distributed-and a mixed effect model that accounts for the autocorrelation between the model residuals. Incorporating autocorrelation through GAMM results in higher smoothing parameters being selected and hence the remaining structure to be accounted for in the residuals increases. This increases the complexity of modeling required for the residuals. Whereas in the TSP, the first stage results in optimally selecting lower smoothing parameters assuming independent errors, which reduces the complexity of modeling required for the residuals in the second stage. After incorporating lagged terms and a simple correlation structure, only a small amount of structure is still remaining between the residuals of the yearly models. Future work could include investigating models such as ARCH/GARCH models to account for the remaining structure in the residuals. Such models are able to capture the varying 
variation in the residual process. Although care has to be taken since autocorrelation can influence smoothing parameter selection from automatic approaches, GAMMs are computationally inefficient with large time series and numerically unstable because of the confounding between correlation and non-linearity. Therefore, alternative methods to fit GAMs with correlated data are required.

In conclusion, these HHFD have illustrated the complex long-term and short-term dynamics of $\mathrm{EpCO}_{2}$ which were previously inaccessible with lower frequency data. However, these HHFD encounter various challenges in terms of statistical modeling and analysis. The challenges facing the description and analysis of such a complex high-resolution datasets must be overcome to avoid limiting insight into, e.g., catchment processes. Among these challenges are (1) the great volumes of data, (2) the complex multivariate interactions between the covariates and the response variable, (3) the complex correlation structures persisting over a large number of lags between observations due to the high-frequency nature of the data, and (4) the identifiability problems in allocating the existing large variability to the signal or noise as a result of the confounding between correlation and non-linearity. Therefore, advanced statistical tools and models are needed to analyze such complex HHFD.

Acknowledgments A.E. is grateful to the Glasgow University sensor studentship for funding. S.W. generated the $\mathrm{EpCO}_{2}$ profiles through Natural Environment Research Council Advanced Fellowship, $\mathrm{NER} / \mathrm{J} / \mathrm{S} / 2001 / 00793$. Stephanie Evers is thanked for field assistance, and SEPA for providing discharge records. S.W. is most grateful to the Fasque Estate, particularly Archie Dykes, for site access and providing accommodation.

Open Access This article is distributed under the terms of the Creative Commons Attribution 4.0 International License (http://creativecommons.org/licenses/by/4.0/), which permits unrestricted use, distribution, and reproduction in any medium, provided you give appropriate credit to the original author(s) and the source, provide a link to the Creative Commons license, and indicate if changes were made.

\section{References}

Bowman A, Azzalini A (1997) Applied smoothing techniques for data analysis: the kernel approach with S-plus illustrations, 1st edn., Oxford Statistical Science SeriesOxford University Press, Oxford

Bowman A, Giannitrapani M, Scott M (2009) Spatiotemporal smoothing and sulphur dioxide trends over Europe. J R Stat Soc 58:737-752

Butman D, Raymond PA (2011) Significant efflux of carbon dioxide from streams and rivers in the United States. Nat Geosci 4:839-842

Cole JJ, Caraco NF, Kling GW, Kratz TK (1994) Carbon dioxide supersaturation in the surface water of lakes. Science 265:1568-1570

Dawson J, Soulsby C, Hrachowitz MS, Telzlaff D (2009) Seasonality of EpCO2 at different scales along an integrated river continuum within the Dee Basin NE Scotland. Hydrol Process 14:2929-2942

Ferguson C, Carvalho L, Scott M et al (2008) Assessing ecological responses to environmental change using statistical models. J Appl Ecol 45(1):193-203

Franco-Villoria M, Scott M, Hoey T, Fischbacher-Smith D (2012) Temporal investigation of flow variability in Scottish rivers using wavelet analysis. J Environ Stat 3(6): 1-20

Hastie TJ, Tibshirani RJ (1990) Generalized additive models, 1st edn., Monographs on statistics and applied probabilityChapman and Hall, London

Intergovernmental Panel on Climate Change IPCC (2013) Climate Change 2013: The Physical Science Basis. http://www.climatechange2013.org/report/. Accessed 20 Mar 2014

Kirchner J, Fang X, Neal C, Robson A (2004) The fine structure of water quality dynamics: the (highfrequency) wave of the future. Hydrol Process 18:1353-1359 
Labat D (2005) Recent advances in wavelet analyses: Part 1. A review of concepts. J Hydrol 314:275-288

Li S, Lu XX, Bush RT (2013) CO2 partial pressure and CO2 emission in the Lower Mekong River. J Hydrol 504:40-56

Li S, Lu XX, He M et al (2012) Daily CO2 partial pressure and CO2 outgassing in the upper Yangtze River basin: a case study of Longchuanjiang. J Hydrol 466-467:141-150

Miller C, Magdalina A, Willows RI et al (2014) Spatiotemporal statistical modelling of long-term change in river nutrient concentrations in England and Wales. Sci Total Environ 466-467:914-923

Moraetis D, Efstathiou D, Stamati F et al (2010) High-frequency monitoring for the identification of hydrological and bio-geochemical processes in a Mediterranean river basin. J Hydrol 389:127-136

Nason GP (2008) Wavelets methods in statistics with R, 1st edn. Springer, Use R!, Berlin

Neal C (1998) Determination of dissolved CO2 in upland streamwater. J Hydrol 99:127-142

Neal C, Reynolds B, Rowland P et al (2012) High-frequency water quality time series in precipitation and streamflow: from fragmentary signals to scientific challenge. Sci Total Environ 434:3-12

Neal C, Reynolds B, Kirchner J et al (2013) High-frequency water quality time series in precipitation and streamflow: from fragmentary signals to scientific challenge. Hydrol Process 27:2531-2539

Percival D, Walden A (2006) Wavelets methods for time series analysis., Cambridge series in statistical and probabilistic mathematicsCambridge University Press, Cambridge

Raymond PA, Caraco NF, Cole JJ (1997) Carbon dioxide concentration and atmoshperic flux in the Hudson River. Estuaries 20:381-390

Richey JE, Melack JM, Aufdenkampe AK et al (2002) Outgassing from Amazonian rivers and wetlands as a large tropical source of atmospheric CO2. Nature 416:617-620

Sen A (2009) Spectral-temporal characterization of river flow variability in England and Wales for the period 1865-2002. Hydrol Process 23:1147-1157

United States Environmental Protection Agency EPA (2012) Water: monitoring and assessment. http:// water.epa.gov/type/rsl/monitoring/vms59.cfm. Accessed 27 May 2014

Waldron S, Scott M, Soulsby C (2007) Stable isotope analysis reveals lower-order river dissolved inorganic carbon pools are highly dynamic. Enviorn Sci Technol 41:6156-6162

Waldron S, Scott M, Vihermaa LE, Newton J (2014) Quantifying precision and accuracy of measurements of dissolved inorganic carbon stable isotopic composition using continuous-flow isotope-ratio mass spectrometry. Rapid Commun Mass Spectrom 28(10):1117-1126

White MA, Schmidt JC, Topping DJ (2005) Application of wavelet analysis for monitoring the hydrologic effects of dam operation: Glen Canyon Dam and the Colorado River at Lees Ferry, Arizona. River Res Appl 21:551-565

Wood SN (2006) Generalized additive models — an introduction with R, 1st edn., Text in statistical science seriesChapman and Hall, London

Wood SN (2011) Fast stable REML and ML estimation of semiparametric GLMs. JRSSB 73:1-34

Wood SN, Goude Y, Shaw S (2015) Generalized additive models for large data sets. JRRSC 64(1):139-155

Yao G, Gao Q, Wang Z et al (2007) Dynamics of CO2 partial pressure and CO2 outgassing in the lower reaches of the Xijiang River, a subtropical monsoon river in China. Sci Total Environ 376:255-266

Yick J, Mukherjee B, Ghosal D (2008) Wireless sensor network survey. Comput Netw 52:2292-2230

Amira Elayouty is an Assistant Lecturer at the Faculty of Economics and Political Science, Cairo University and currently a Ph.D student in Statistics, in the School of Mathematics and Statistics at the University of Glasgow, Glasgow, UK, G12 8QW (a.el-ayouti.1@research.gla.ac.uk). Her research interests include spatio-temporal models, non-parametric regression and additive models with a particular focus on environmental statistics.

Marian Scott is a Professor of Environmental Statistics, in the School of Mathematics and Statistics at the University of Glasgow, Glasgow, UK, G12 8QW (marian.scott@ glasgow.ac.uk). Her research interests include varying-coefficient and additive models, spatiotemporal models, quantile regression and functional data analysis.

Claire Miller is a Senior Lecturer in Statistics, in the School of Mathematics and Statistics at the University of Glasgow, Glasgow, UK, G12 8QW (claire.miller@glasgow.ac.uk). Her research interests include 
nonparametric, varying-coefficient and additive models, environmetrics, spatiotemporal models and functional data analysis.

Susan Waldron holds a personal chair in Biogeochemistry and heads the Carbon Landscape Research Group (www.carbonlandscapes.org). A geologist by training, her research focuses on the carbon cycle particularly transfer of $\mathrm{C}$ from the terrestrial environment to aquatic systems and from there to the atmosphere. A key focus of her research is environmental resilience and response to hosting energy production and land-based renewable and using sensor technology to capture the detail of the environmental response.

Maria Franco-Villoria is a research assistant in Statistics, in the Department of Economics and Statistics at the University of Turin, Italy (maria.francovilloria@unito.it). Her research interests include environmental statistics and functional data analysis. 